\title{
Hypertension in Children and Adolescents
}

\author{
${ }^{1}$ IB Vijayalakshmi, ${ }^{2}$ Chitra Narasimhan
}

\begin{abstract}
Introduction: Pediatric hypertension has been recognized as an important health issue over the past years. In children though the etiology of hypertension is predominantly secondary, the prevalence of primary hypertension has been increasing at an alarming rate, particularly in adolescents and older children.
\end{abstract}

Discussion: The prevalence of hypertension in children increases with increasing body mass index percentile, placing obese children at three times higher risk of becoming hypertensive. It has been shown that weight loss by itself can decrease blood pressure and other associated cardiovascular risk factors should also be expected to regress or improve with weight loss. Dietary changes can involve portion-size control, decrease in consumption of sugar-containing beverages, energy-dense snacks, increase in consumption of fresh fruits, vegetables, low-fat dairy, stopping smoking and abstinence from alcohol use. Secondary hypertension due to specific conditions can be controlled and treated successfully by appropriate timely interventions both surgical and nonsurgical.

Conclusion: Pediatric hypertension is a serious disease that should be neither overlooked nor ignored. The evaluation and treatment of hypertension in childhood has continued to evolve over the past four decades. There is a great need to diagnose and treat hypertension when it develops in childhood to decrease the risk of cardiovascular morbidity in adulthood.

Keywords: Aortic stenting, Aortoarteritis, Coarctoplasty, Coil occlusion of renal artery, Renal artery angioplasty.

How to cite this article: Vijayalakshmi IB, Narasimhan C. Hypertension in Children and Adolescents. Hypertens $\mathrm{J}$ 2015;1(2):88-93.

\section{Source of support: Nil}

\section{Conflict of interest: None}

\section{INTRODUCTION}

Pediatric hypertension has been classified as primary (essential) or secondary to, e.g. renal parenchymal, renovascular, coarctation of aorta (COA) or an endocrine

\footnotetext{
${ }^{1}$ Former Professor and Head, ${ }^{2}$ Assistant Professor

1,2Department of Pediatric Cardiology, Sri Jayadeva Institute of Cardiovascular Sciences and Research, Bengaluru Karnataka, India

Corresponding Author: IB Vijayalakshmi, Former Professor and Head, Department of Pediatric Cardiology, Sri Jayadeva Institute of Cardiovascular Sciences and Research, Bengaluru Karnataka, India, Phone: 094484940984, e-mail: docvj@yahoo.com
}

disorder. ${ }^{1}$ In children though the etiology of hypertension is predominantly secondary, the prevalence of primary hypertension has been increasing at an alarming rate particularly in adolescents and older children. This is partially because of the increasing prevalence of pediatric obesity, change in dietary habits to increased intake of high calorie, high-salt foods, decreased physical activity and increasing stress. Elevated blood pressure (BP) at a young age is a predictor of BP elevation later in life. ${ }^{2,3}$

\section{EPIDEMIOLOGY}

About two to three decades ago, pediatric hypertension was found in only 0.3 to $1.2 \%$ of children, ${ }^{4,5}$ but it is now seen in 3.2 to $4.5 \%$ of all children and in up to $30 \%$ of overweight children. ${ }^{6-8}$ The number of children with prehypertension also has increased from 7.7 to $15.7 \%{ }^{8,9}$ A few studies in India have reported the prevalence of hypertension in childhood and/or adolescence ranging from 1.53 to $10.58 \%{ }^{10}$

\section{DEFINITION AND CLASSIFICATION}

The National High Blood Pressure Education Program (NHBPEP) Working Group established guidelines for the definition of normal and elevated BP in children in $1987^{11}$ and these were updated in $2004 .^{3}$ In children, the definition is based upon the normal distribution of BP in healthy children, unlike in adults which is primarily defined by clinical outcome data (i.e. risk of cardiovascular disease and mortality) from large trials of antihypertensive therapy., ${ }^{3,11,12}$ The classification of BP is more accurate when the values are adjusted for height as well as age and gender to avoid misclassifying children at the extremes of normal growth.,13

As per the NHBPEP guidelines, hypertension in children and adolescents is defined as average of systolic $\mathrm{BP}$ (SBP) and/or diastolic BP (DBP) that is $>95$ th percentile for gender, age and height on $>3$ occasions. The high BP reading should be obtained at three or more separate office visits about 1 week apart. A patient with BP levels $>$ 95th percentile in a physician's office or clinic, who is normotensive outside a clinical setting, has 'white-coat hypertension.' Ambulatory BP monitoring (ABPM) is usually required to make this diagnosis. The fourth report provides criteria for staging the severity of hypertension in children and adolescents in stage 1 hypertension 
Hypertension in Children and Adolescents

Table 1: Classification of hypertension in children and adolescents ${ }^{3}$

\begin{tabular}{lll}
\hline Stages & SBP or DBP percentile* & Frequency of BP measurement \\
\hline $\begin{array}{l}\text { Normal } \\
\text { Prehypertension }\end{array}$ & $\begin{array}{l}<90 \text { th } \\
\geq 90 \text { th-<95th or if BP } \\
\geq 120 / 80 \mathrm{~mm} \mathrm{Hg} \mathrm{for} \mathrm{adolescents} \\
\text { Stage } 1 \text { hypertension }\end{array}$ & $\begin{array}{l}\text { Recheck at next scheduled physical examination } \\
\text { Recheck in } 6 \text { months }\end{array}$ \\
& & $\begin{array}{l}\text { Recheck in 1-2 weeks or sooner if the patient } \\
\text { is symptomatic; if persistently elevated on } \\
\text { two additional occasions, evaluate or refer to } \\
\text { source of care within } 1 \text { month }\end{array}$ \\
Stage 2 hypertension & $>99$ th percentile plus $5 \mathrm{~mm} \mathrm{Hg}$ & $\begin{array}{l}\text { Evaluate or refer to source of care within } 1 \text { week } \\
\text { or immediately if the patient is symptomatic }\end{array}$ \\
\hline
\end{tabular}

BP: Blood pressure; DBP: Diastolic blood pressure; SBP: Systolic blood pressure; *All BP percentiles are based on sex, age, and height percentiles

and stage 2 hypertension, which can be used clinically to guide evaluation and management (Table 1). ${ }^{3}$

It is recommended that children $>3$ years old should have their BP measured at least once during every healthcare visit. Younger children should have their BP measured in special circumstances like history of prematurity, congenital heart disease, known renal disease or urologic malformations, malignancy, solidorgan transplant, other systemic illnesses and drugs known to be associated with elevated $\mathrm{BP}^{3}$

\section{METHOD OF RECORDING BP}

The preferred method of BP measurement is by auscultatory method, using appropriate sized cuffs. The width of inflatable bladder should be at least $40 \%$ of the arm circumference at a point midway between the olecranon and the acromion and its length 80 to $100 \%$ of the circumference of the arm. Bladder width-to-length ratio should be at least 1:2. The first Korotkoff sound should be taken as systolic BP and the disappearance of sound is taken as diastolic BP. The reference standards to be used for children between 1 and 17 years of age are published charts by the fourth task force, which depends on gender, age and height. ${ }^{3}$ The systolic and diastolic norms depend on the height percentile. For children below 1 year, the data provided by the second task force is used. ${ }^{11}$

Ambulatory BP monitoring is done using a portable device worn by the patient to record BP over a specific period. It enables one to measure the mean daily BP over 24 hours, including degree of nocturnal dipping and nondipping patterns. It is now been increasingly recognized as being indispensable to the diagnosis and management of hypertension, in children of 5 years or older. $^{3,14,15}$

\section{CAUSES OF CHILDHOOD HYPERTENSION}

The causes of elevated BP are multiple and the various causes of BP elevation in children according to age group are given in Table 2.
Table 2: Causes of blood pressure elevation in children according to age group

\begin{tabular}{ll}
\hline Age & Causes \\
\hline Newborn and first year of life & Secondary (99\%)- \\
& Coarctation of the aorta, \\
& renovascular (renal artery/ \\
& vein thrombosis, renal artery \\
& stenosis), renal parenchymal \\
& disease, neoplasia (4\%), \\
& pheochromocytoma, \\
& endocrine (1\%), cushing \\
& disease \\
& Secondary (70-85\%)- \\
& renal parenchymal disease, \\
& coarctation of the aorta, \\
& aortoarteritis (e.g. case 2) \\
& reflux nephropathy, \\
& renovascular, endocrine, \\
1-12 years & neoplasia, primary \\
& (essential-15-30\%) \\
& Primary (essential-85-95\%) \\
& Secondary (5-15\%)-same \\
causes as 1-12-year-old
\end{tabular}

\section{EVALUATION}

A careful history and physical examination can provide clues to detect secondary causes of hypertension or make a diagnosis of essential hypertension. Most cases of high BP are detected during routine physical examinations. Mild to moderate hypertension is most commonly asymptomatic but may be associated with subtle changes in behavior or school performance or child may have other medical problems like obesity, high blood lipids and/or diabetes mellitus. With consistent or severe elevations of BP, they may have symptoms of frequent headaches, dizziness, changes in vision or may present with emergencies like seizures and encephalopathy. In infants, behavioral cues, such as increased irritability or head rubbing/banging may be noted and patients with severe hypertension can present with symptoms of congestive heart failure, such as irritability, respiratory distress, feeding difficulties and failure to thrive. Some of the important history and physical examination findings are given in Box $1 .^{16}$ 


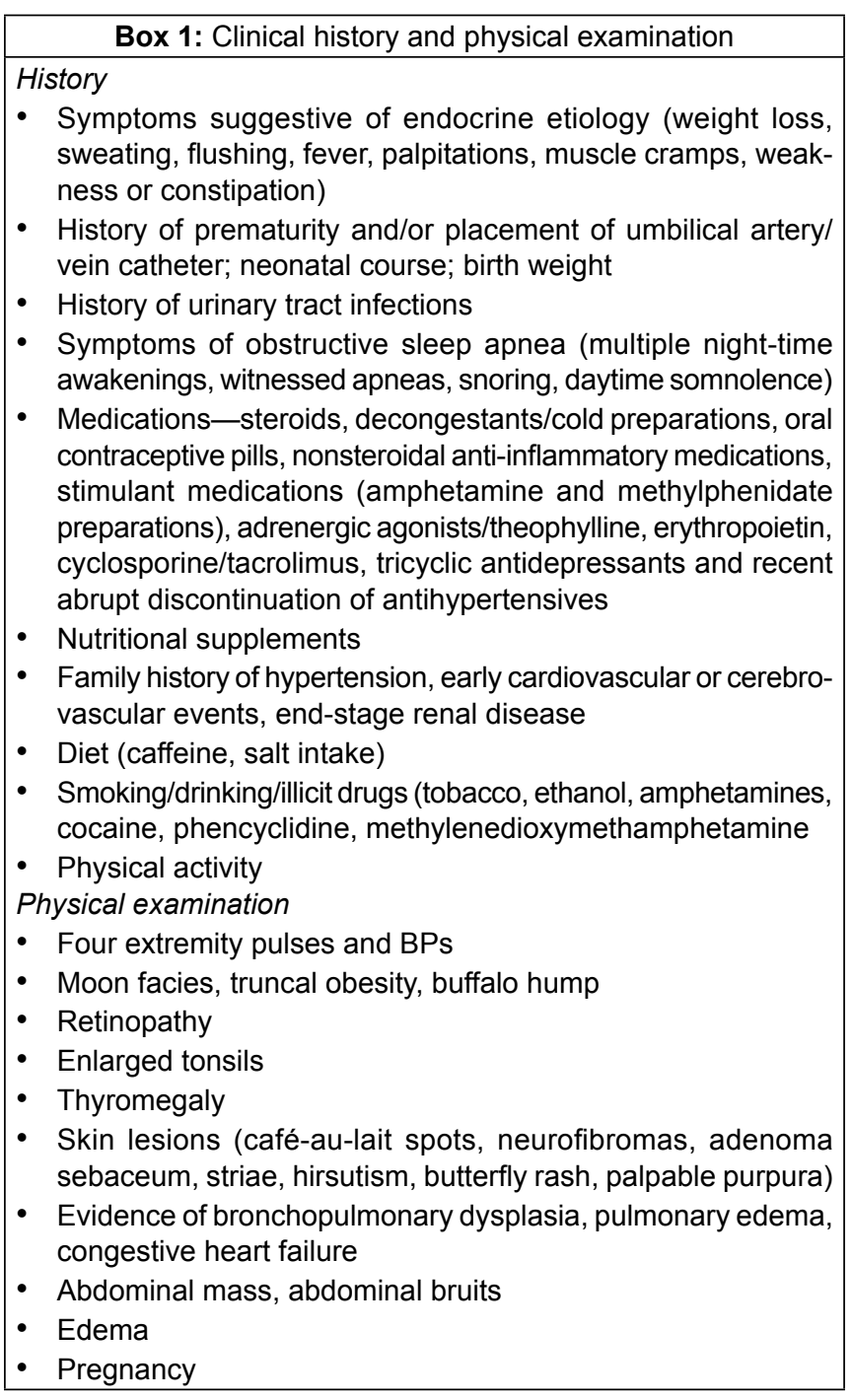

All hypertensive children should undergo the initial laboratory and radiologic investigations as given in Box 2. ${ }^{3,16}$ The most common indication of end-organ damage in hypertensive children is left ventricular hypertrophy (LVH). In pediatric population, $\mathrm{LVH}$ is diagnosed by left ventricular mass (LVM), measured by echocardiography and indexed to height (LVMI) to correct for body size. A conservative cut-off point of LVMI is $51 \mathrm{gm} / \mathrm{m}^{2}$, which is $>99$ th percentile for children and adolescents and is associated with increased morbidity in adults with hypertension. ${ }^{17,18}$

\section{TREATMENT STRATEGIES}

The goal of treatment is to reduce BP to a level below the 90th percentile and prevent development of targetorgan damage. There are two therapeutic options used to manage primary hypertension in children, namely lifestyle modification and pharmacological therapies.

Children with prehypertension or asymptomatic, stage 1 primary hypertension who do not have evidence of end-organ damage or diabetes, should be 'prescribed'

\begin{tabular}{|l|}
\hline \multicolumn{1}{|c|}{ Box 2: Laboratory evaluation and imaging } \\
\hline Laboratory evaluation \\
- Basic metabolic panel (electrolytes, blood urea nitrogen, \\
bicarbonate, creatinine levels), urinalysis and urine culture \\
to rule out renal disease and chronic pyelonephritis \\
- Complete blood count to rule out anemia, which would be \\
consistent with chronic renal disease \\
- Fasting lipids and glucose to identify lipid and/or metabolic \\
abnormalities \\
- Thyroid function tests to rule out thyroid disease \\
Plasma renin activity: very young with stage 1 and children \\
Imaging \\
- Renal ultrasound with Doppler examination of the renal \\
vasculature \\
Renovascular imaging-isotopic scintigraphy (renal scan), \\
magnetic resonance angiography (MRA), Duplex Doppler \\
flow studies, 3-dimensional CT \\
Arteriography: digital-subtraction angiography (DSA) or \\
classic. Renal arteriography is gold standard for diagnosing \\
renal artery stenosis in children \\
Other tests \\
- Echocardiography including measurement of left ventricular \\
mass index (LVMI) \\
- Retinal exam in severe cases \\
Assessment of catecholamines
\end{tabular}

lifestyle modifications and be re-evaluated in 6 months. Then if there is still persistent hypertension an antihypertensive medication should be started. Similarly, any child with symptomatic hypertension, stage 2 hypertension, secondary hypertension, diabetes or evidence of end organ damage should be started on an antihypertensive medication. Even if the child is on antihypertensive medication nonpharmacologic lifestyle interventions should continue to be emphasized at each visit, particularly in overweight or obese children. ${ }^{3}$

\section{LIFESTYLE MODIFICATION}

Weight reduction is the primary therapy for obesityrelated hypertension. Regular physical activity and restriction of sedentary activity will improve efforts at weight management and may prevent an excess increase in BP over time and a reduced risk of hypertension 16 to 50 years later. ${ }^{19}$ Since most children view their guardians or siblings as role models, it is often beneficial to apply lifestyle modification to the entire household (familybased intervention). This may increase the likelihood of adherence. Some of the nonpharmacological interventions are given in Box $3 .^{3}$

\section{PHARMACOLOGIC THERAPIES}

Children who have symptomatic essential hypertension, secondary hypertension, diabetes-associated hypertension, evidence of target-organ damage (LVH) or failed nonpharmacologic intervention require pharmacologic therapy. ${ }^{3}$ The goal for antihypertensive treatment in 


\begin{tabular}{|l|}
\hline Box 3: Nonpharmacologic interventions \\
\hline - Aerobic exercise: $30-45$ minutes most days of the week \\
- Limit sedentary activities like watching television and playing \\
video or computer games to less than 2 hours/day \\
- Weight reduction if overweight \\
- Increased intake of fresh vegetables, fruits and low-fat dairy \\
(the dietary approaches to stop hypertension (DASH) study \\
eating plan) \\
- Salt restriction* \\
- Adequate intake of potassium and calcium (both shown to \\
- Cesse antihypertensive effects)
\end{tabular}

${ }^{*}$ Can start with recommending no added salt, with the ultimate goal of achieving the current recommendation of $1.2 \mathrm{gm} /$ day total for 4 to 8 -year-old and $1.5 \mathrm{gm} /$ day total for children 9 years of age and older

children should be reduction of BP to <95th percentile unless concurrent conditions are present, in which case BP should be lowered to $<90$ th percentile. The various drugs and doses are available in the guidelines. ${ }^{2,3}$ Drug options for initial therapy for hypertension in children is given in Table $3 .^{20} \mathrm{ACE}$ inhibitors and ARBs should be avoided in patients with renal artery stenosis and females of childbearing age as they are highly teratogenic. The choice of medication in children depends on the etiology of hypertension, anticipated benefits and the potential adverse effects. ${ }^{21}$ If hypertension is primary, the initial drug of choice should be an ACE-I, an ARB or a CCB. They are most common antihypertensive medications prescribed currently across all pediatric ages. These

Table 3: Drug options for initial therapy for hypertension in children ${ }^{20}$

\begin{tabular}{ll}
\hline Class of drugs & Patients' characteristics \\
\hline ACE-I/ARB & First-line therapy. High plasma renin \\
& activity, unilateral renovascular \\
& hypertension, renal parenchymal \\
& disease, renal proteinuria, congestive \\
& heart failure, diabetes mellitus, gout, \\
& hyperlipidemia, reactive airway disease. \\
& Avoid in pregnancy and renal artery \\
& stenosis \\
CCB & First-line therapy. Emergency \\
& hypertension (nifedipine), black race, \\
& diabetes mellitus, chronic obstructive \\
& lung disease, bronchopulmonary \\
& dysplasia, gout, hyperlipidemia, \\
peripheral vascular disease. Renal \\
transplant, therapy with anticalcineurin \\
Adjunct second-line drug. Volume- \\
dependent, low plasma renin activity, \\
black race, oral contraceptive therapy, \\
congestive heart failure. Avoid in athletes \\
Contracted intravascular volume, high \\
plasma renin activity, hyperdynamic \\
circulation, anxiety, migraine \\
(propranolol, nadolol), hyperthyroidism, \\
neuroadrenergic tumors. Avoid in athletes \\
and people with diabetes
\end{tabular}

ACE-I: Angiotensin converting enzyme inhibitor; ARB: Angiotensin receptor blockers; CCB: Calcium channel blocker drugs are available in once-a-day dosage and have fewer side effects, both features reflecting positively on adherence. The use of an ACEI or ARB is favored in patients with diabetes and microalbuminuria or proteinuric renal disease because of their renoprotective effect. Calcium channel blocker is a good option in patients with diabetes or metabolic syndrome as they improve insulin sensitivity. Calcium channel blockers or $\beta$-blockers are frequently used in children with migraine headaches. Diuretics are often used as second-line drugs and in combination with others. Diuretics and $\beta$-blockers should be avoided in athletes. If monotherapy fails to correct BP within 2 weeks, despite adherence and use of the maximal amount of the drug, a diuretic or a second drug from another class can be added. A final step is to use a potent vasodilator like minoxidil or a centrally acting agent like clonidine. Often, combination therapy with a diuretic or from a different antihypertensive class is needed to achieve effective control of BP. Treatment of severe hypertension, especially when associated with encephalopathy or congestive heart failure (CHF), requires hospital admission.

\section{INTERVENTIONS FOR SECONDARY HYPERTENSION}

Many centers use angioplasty as first-line treatment for renovascular hypertension in children and use surgery as second-line treatment when angioplasty has failed or when it is not technically feasible. Surgery should be considered as possible first-line treatment, however, if there is stenosis $>10 \mathrm{~mm}$ or multiple stenosed large vessels, or if mid aortic stenosis (MAS) is present in association with severe widespread disease, including bilateral renal artery stenosis (Figs 1A to D). Of note, in children who have significant intrarenal disease, seemingly successful treatment of main-artery stenoses may fail to improve the $\mathrm{BP}^{22}$

The other treatment modalities for resistant renal hypertension due to end stage renal disease include surgical nephrectomy, medical nephrectomy, radiofrequency ablation of renal nerve supply in patients with nonfunctioning kidneys. Now renal artery coil embolization for sustained hypertension (Case 1, Figs $2 \mathrm{~A}$ and $\mathrm{B}$ ) is possible. ${ }^{23-25}$

In the past few decades nonsurgical catheter-based interventions have become attractive alternative to control secondary hypertension in some subset of patients, e.g. COA (Case 2), aortoarteritis ${ }^{26}$ (Figs 3A to D), renal artery stenosis, etc.

\section{Case 1}

A 4 years old male child presented with excessive sweating and generalized weakness of 20 days duration. On examination, the pulse rate was 98 /minute, regular, 

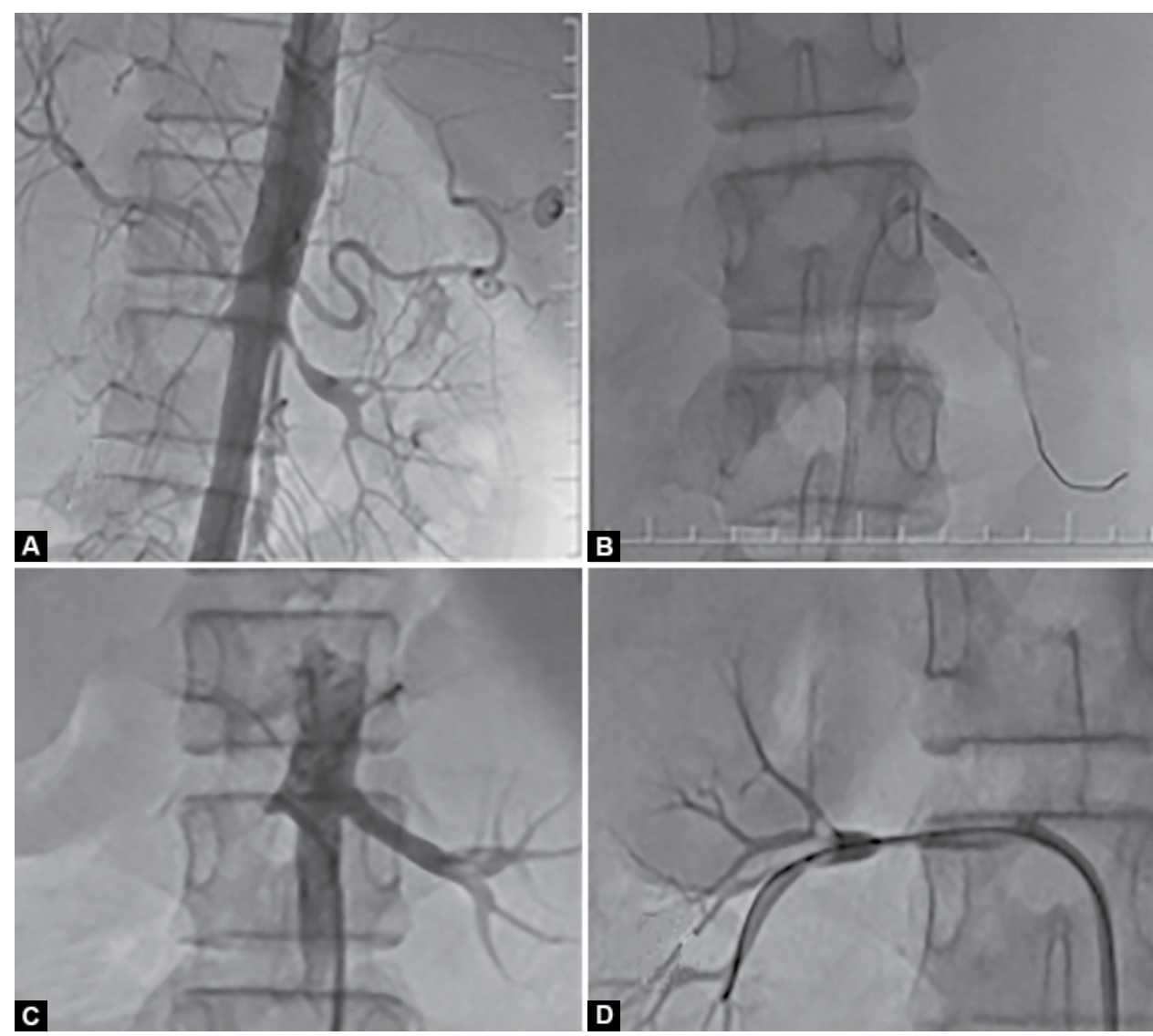

Figs 1A to D: (A) Abdominal aorta angiogram shows $100 \%$ obstruction of right renal artery, left renal artery shows $80 \%$ stenosis of left renal artery, (B) inflated balloon across left renal artery, (C) check angio shows well opened left renal artery after stenting and (D) selective right renal artery angio after balloon dilatation shows partially opened artery

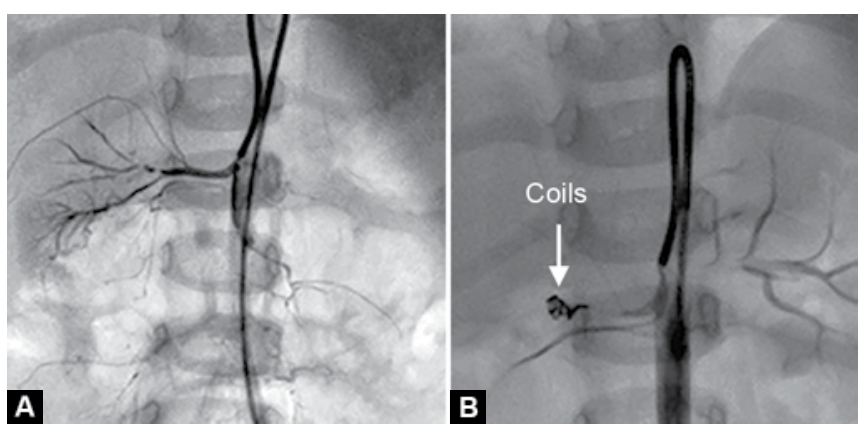

Figs 2A and B: (A) Selective angiogram with Simon's catheter shows diffusely narrow right renal artery with multiple blocks and (B) check angio shows $5 \times 3$ and $3 \times 4$ embolization coils in situ with complete closure of right renal artery and visualization of small aberrant renal artery to lower pole of right kidney

good volume, all peripheral pulses were well felt. The $\mathrm{BP}$ was 240/120 mm Hg in right upper limb and 250/126 $\mathrm{mm} \mathrm{Hg}$ in lower limb despite the maximum dose of oral furosemide, amlodipine and metoprolol. The ultrasound of the abdomen revealed a small contracted right kidney. The renal angiogram showed normal left renal artery and the long segment diffuse narrowing of the right renal artery not suitable for balloon angioplasty. The renal DTPA demonstrated $20 \%$ functioning of right kidney and $80 \%$ functioning of the left kidney. Despite of high optimal doses of three antihypertensive drugs, the

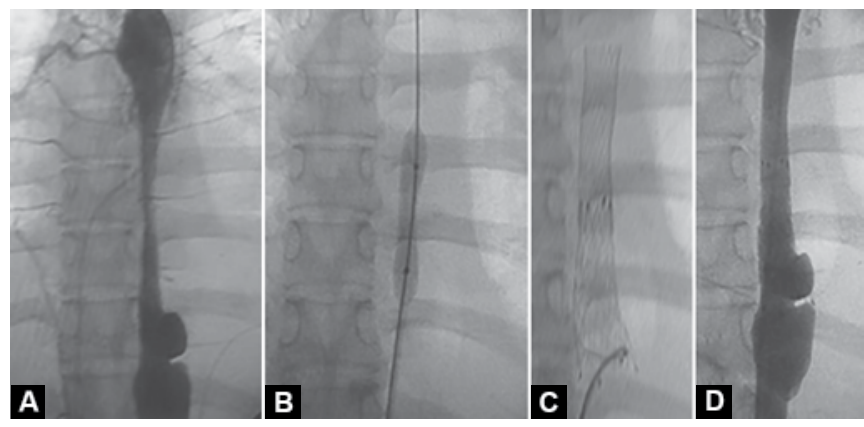

Figs 3A to D: (A) Aortic angio shows midthoracic aorta diffuse narrowing, (B) shows inflated balloon with waist, (C) two Bard selfexpandable stents $14 \times 40 \mathrm{~mm}$ telescoped one into another and (D) check angio shows opened up mid thoracic aorta with small aneurysm distally, in 14 years old girl who presented in NYHA class IV and echo showed dilated left ventricle, with reduced global left ventricular function with ejection fraction of $30 \%$

patient continued to have very high $\mathrm{BP}(240 / 120 \mathrm{~mm} \mathrm{Hg})$. In view of the resistant hypertension, pediatric surgeon deferred surgery and referred the patient for possible nonsurgical coil closure. The Cooks $3 \times 4 \mathrm{~mm}$ and $3 \times$ $5 \mathrm{~mm}$ embolization coils were deployed at the distal end of right main renal artery using the 0.035 straight guide wire to push the coils in position. The check renal angiogram (Figs 2A and B) showed complete occlusion of the right renal artery. The $\mathrm{BP}$ on discharge was 136/90 mm Hg in the upper limb and 146/94 in the lower limb. 


\section{Case 2}

A 42 days old boy was diagnosed as dilated cardiomyopathy with LV failure was treated with IV inotropes. On recording, the BP in upper limb was 220/120 mm Hg. Lower limb pulse not felt BP was not recordable. So, obviously diagnosis of COA was missed. The infant was taken up for emergency aortoplasty. Coarctoplasty gives excellent palliation in sick neonate with left ventricular failure. In this child ejection, fraction improved from 35 to $55 \%$. Though immediate success rate is 85 to $100 \%$, restenosis is $40 \%$. But, it is lifesaving with excellent results beyond 1 year and restenosis is as low as just 7 to $8 \%$. Excellent for postoperative restenosis.

\section{CONCLUSION}

Pediatric hypertension is a serious disease that should be neither overlooked nor ignored. The evaluation and treatment of hypertension in childhood has continued to evolve over the past four decades. The genetic verification of selected forms of hypertension, newer imaging modalities and improved antihypertensive drugs has provided a more focused approach to pediatric hypertension. Despite these advances, the basic requirements for detecting and evaluating the hypertensive youth remains a thorough history and physical examination.

\section{REFERENCES}

1. Bagga A, Jain R, Vijayakumar M, Kanitkar M, Ali U. Evaluation and management of hypertension. Ind Pediatr 2007;44(2):103-121.

2. Lurbe E, Cifkova R, Cruickshank JK, et al. Management of high blood pressure in children and adolescents: recommendations of the European Society of Hypertension. J Hypertens 2009;27(9):1719-1742.

3. National High Blood Pressure Education Program Working Group on High Blood Pressure in Children and Adolescents. The Fourth report on the diagnosis, evaluation, and treatment of high blood pressure in children and adolescents. Pediatrics 2004;114(2 Suppl 4th Report):555-576.

4. Fixler DE, Laird WP, Fitzgerald V, Stead S, Adams R. Hypertension screening in schools: results of the Dallas study. Pediatrics 1979;63(1):32-36.

5. Sinaiko AR, Gomez-Marin O, Prineas RJ. Prevalence of 'significant' hypertension in junior high school-aged children: the children and adolescent blood pressure program. J Pediatr 1989;114(4 Pt 1):664-669.

6. Sorof JM, Lai D, Turner J, Poffenbarger T, Portman RJ. Overweight, ethnicity, and the prevalence of hypertension in school-aged children. Pediatrics 2004;113(3Pt 1):475-482.

7. Sorof J, Daniels S. Obesity hypertension in children: a problem of epidemic proportions. Hypertension 2002;40(4):441-447.

8. McNiece KL, Poffenbarger TS, Turner JL, Franco KD, Sorof JM, Portman RJ. Prevalence of hypertension and pre-hypertension among adolescents. J Pediatr 2007;150(6): 640-644, 644.e1.
9. Din-Dzietham R, Liu Y, Bielo MV, Shamsa F. High blood pressure trends in children and adolescents in national surveys, 1963 to 2002. Circulation 2007;116(13):1488-1496.

10. Raj M, Krishnakumar R. Hypertension in children and adolescents: epidemiology and pathogenesis. Ind J Pediatr 2013;80(Suppl 1):S71-S76.

11. Report of the Second Task Force on Blood Pressure Control in Children-1987. Task Force on Blood Pressure Control in Children. National Heart, Lung, and Blood Institute, Bethesda, Maryland. Pediatrics 1987;79(1):1-25.

12. James PA, Oparil S, Carter BL, et al. Evidence-based guideline for the management of high blood pressure in adults: report from the panel members appointed to the Eighth Joint National Committee (JNC 8). JAMA 2014;311(5):507.

13. Rosner B, Prineas RJ, Loggie JM, Daniels SR. Blood pressure nomograms for children and adolescents, by height, sex, and age, in the United States. J Pediatr 1993;123(6):871.

14. Lurbe E, Torro MI, Alvarez J. Ambulatory blood pressure monitoring in children and adolescents: coming of age? Curr Hypertens Rep 2013;15(3):143-149.

15. Urbina E, Alpert B, Flynn J, Hayman L, Harshfield GA, Jacobson $\mathrm{M}$, et al. Ambulatory blood pressure monitoring in children and adolescents: recommendations for standard assessment: a scientific statement from the American Heart Association Atherosclerosis, Hypertension, and Obesity in Youth Committee of the council on cardiovascular disease in the young and the council for high blood pressure research. Hypertension 2008;52(3):433-451.

16. Brady TM, Feld LG. Pediatric approach to hypertension. Semin Nephrol 2009;29(4):379-388.

17. Chobanian AV, Bakris GL, Black HR, et al. The seventh report of the joint national committee on prevention, detection, evaluation, and treatment of high blood pressure: the JNC 7 report. JAMA 2003;289(19):2560-2572.

18. de Simone G, Daniels SR, Devereux RB, et al. Left ventricular mass and body size in normotensive children and adults: assessment of allometric relations and impact of overweight. J Am Coll Cardiol 1992;20(5):1251-1260.

19. Paffenbarger RS Jr, Wing AL, Hyde RT, Jung DL. Physical activity and incidence of hypertension in college alumni. Am J Epidemiol 1983;117(3):245-257.

20. Seikaly MG. Hypertension in children: an update on treatment strategies. Curr Opin Pediatr 2007;19(2):170-177.

21. Stephens MM, Fox BA, Maxwell L. Therapeutic options for the treatment of hypertension in children and adolescents. Clin Med Insights Circ Respir Pulm Med 2012;6:13-25.

22. Meyers KE, Cahill AM, Sethna C. Interventions for pediatric renovascular hypertension. Curr Hypertens Rep 2014;16(4):422.

23. Sauk S, Zuckerman DA. Renal artery embolization. Semin Intervent Radiol 2011;28(4):396-406.

24. Hom D, Eiley D, Lumerman JH, Siegel DN, Goldfischer ER, Smith AD. Complete renal embolization as an alternative to nephrectomy. J Urol 1999;161(1):24-27.

25. Vijayalakshmi IB, Kariyappa M, Agarwal N, et al. Renal artery coil embolization of a non-functional kidney: a novel method to treat resistant hypertension in paediatric patients. J Ind College Cardiol 2015;5(3):231-234.

26. Vijayalakshmi. Recent advances in management in of nonspecific aorto arteritis. Ind J Pediatr 2002;69(6):523-526. 